\title{
The Catalytic Role of Nitrogen-Doped Carbon Nanotubes in Bioleaching Copper from Waste Printed Circuit Boards
}

\author{
Jianfeng Bai ${ }^{1,2 *}$, Weihua Gu ${ }^{1,2}$, Jue Dai ${ }^{3}$, Chenglong Zhang ${ }^{1,2}$, Wenyi Yuan ${ }^{1,2}$, \\ Mingqiang Deng ${ }^{4}$, Xinyun Luo ${ }^{4}$, Jingwei Wang ${ }^{1,2}$ \\ ${ }^{1}$ Shanghai Collaborative Innovation Centre for WEEE Recycling, Shanghai 201209, PR China \\ ${ }^{2}$ WEEE Research Centre of Shanghai Polytechnic University, Shanghai 201209, PR China \\ ${ }^{3}$ School of Environmental and Materials Engineering of Shanghai Polytechnic University, Shanghai 201209, PR China \\ ${ }^{4}$ Senlan Environmental (Shanghai) Co., Ltd, Shanghai 201204, PR China
}

Received: 28 December 2015

Accepted: 16 February 2016

\begin{abstract}
The objective of this research was to investigate the catalytic role of nitrogen-doped carbon nanotubes (NCNTs) in a bioreactor that contained Acidithiobacillus ferrooxidans (A. ferrooxidans) and waste printed circuit boards (WPCB). Factors that could reflect the results, such as $\mathrm{pH}$, oxidation-reduction potential (ORP), $\mathrm{Fe}^{2+}$, and leaching rate of copper were detected and calculated in the bioleaching process. The results demonstrated that a certain amount of NCNTs had good compatibility with A. ferrooxidans, and it had the best consistency when added to $0.04 \mathrm{~g}$ NCNTs in $50 \mathrm{ml}$ solution. NCNTs could promote nearly $10 \%$ of copper leaching rate from WPCB by A. ferrooxidans compared with the blank group. When the NCNTs were treated by acid solution, its ability to promote the leaching rate of copper had a certain degree of decline (but not obvious), and it was about $2 \%$ lower than the group in which the NCNTs were not treated with acid. These phenomena could expand the application of NCNTs, and these could provide a basis for the next industrial application of $A$. ferrooxidans.
\end{abstract}

Keywords: waste printed circuit boards, nitrogen-doped carbon nanotubes, Acidithobacillus ferrooxidans, bioleaching, copper

\section{Introduction}

According to statistics, about 20-50 million tons of electronic waste are generated annually, and most electronic waste contains printed circuit boards [1]. Mainly, the printed circuit boards consist of organic resins, metals, and glass

*e-mail: jfbai@imail.sspu.edu.cn fibre [2], therefore there are lots of recyclable resources within WPCBs. When these WPCBs are disposed of improperly, they will not only pollute the environment, but also endanger human health. With the reduction in global metal resources, the extraction of metals from WPCBs is considered to be promising research.

In 1947 Arthur Colmer [3] found a bacteria from acidic mine water that could oxidize $\mathrm{Fe}^{2+}$ to $\mathrm{Fe}^{3+}$. The bacteria was named $A$. ferrooxidans and was widely used in ore 
leaching fields [4-5]. Currently, lots of research has shown that leaching copper from WPCB by $A$. ferrooxidans is a feasible method, and it's a technology with low energy consumption and no generation of "secondary pollution" [6-10]. However, the valence state of metals in ore and WPCB is different, so the mature microbiological techniques in ore are not well suited to bioleaching from WPCB. At present, a widespread problem about leaching copper from WPCB by A. ferrooxidans exists, and leaching efficiency is low [11-12]. It is imperative to explore a new way to assist $A$. ferrooxidans in bioleaching copper from WPCBs.

The NCNT has a one-dimensional tubular structure and is made up of single-layer or multi-layer grapheme [13]. Due to its great specific surface area, good adsorption, and good electronic and heat transfer [14-17], NCNTs have been widely applied as catalyst carriers in catalyst fields. Research has shown that the growth of bacteria will be inhibited by excessive CNTs [18].

The objective of this study is to increase the contact area and speed up the reaction between A. ferrooxidans and WPCB powder. Based on the special properties of NCNTs, we explored the catalytic role of NCNTs in bioleaching copper from WPCB by $A$. ferrooxidans. In order to recover material, the reuse feasibility of NCNTs after the bioleaching reaction was investigated.

\section{Material and Methods}

\section{Source and Description of WPCBs and NCNTs}

WPCB was provided by an electronic waste recycling company in Shanghai. The sample was crushed into small particle sizes by a grinder (DF-40, BILON, China) and pretreated by saturated brine so that metals and non-metals could separate as much as possible. Then it was washed by distilled water and dried at $60^{\circ} \mathrm{C}$ for $24 \mathrm{~h}$. All WPCB particle sizes used in this study were less than $1 \mathrm{~mm}$. NCNTs were provided by the College of Environment and Material Engineering in Shanghai Polytechnic University. NCNTs were dried prior to use.

\section{Microorganism and Reagents}

A. ferrooxidans used in this study were isolated from acidic mine drainage from Dexing Mine, Jiangxi province,
China. The bacteria were grown in $9 \mathrm{~K}$ medium with its components: $\left(\mathrm{NH}_{4}\right)_{2} \mathrm{SO}_{4} 3.0 \mathrm{~g}, \mathrm{KCL} 0.1 \mathrm{~g}, \mathrm{MgSO}_{4} \cdot 7 \mathrm{H}_{2} \mathrm{O}$ $0.5 \mathrm{~g}, \mathrm{~K}_{2} \mathrm{HPO}_{4} 0.5 \mathrm{~g}, \mathrm{FeSO}_{4} \cdot 7 \mathrm{H}_{2} \mathrm{O} 40 \mathrm{~g}, \mathrm{Ca}\left(\mathrm{NO}_{3}\right)_{2} 0.01 \mathrm{~g}$, $1000 \mathrm{ml}$ distilled water (adjusted to $\mathrm{pH}$ value 2.5 by sulfuric acid). All aqueous solutions were prepared by distilled water.

\section{Characterization of WPCBs}

The elements contained in WPCBs were detected by chemical analysis. Different particle sizes of WPCB powder were digested by aqua regia at $90^{\circ} \mathrm{C}$ for $2 \mathrm{~h}$, then diluted by distilled water and analyzed using an inductively coupled plasma-atomic emission spectrometer (A6300, Thermo, USA; Table 1.)

\section{Acclimatization of $A$. ferrooxidans}

In order to improve $A$. ferrooxidans' resistance to copper ions, the content of copper ions in culture medium was increased each time.

\section{Different Methods of Bioleaching}

In order to investigate the catalytic role of NCNTs in the bioleaching process, three things needed to be done:

1. The experiment should be done to determine whether or NCNTs inhibited the normal growth of A. ferrooxidans.

2. Experiments were conducted with three conditions: (i) only bacteria was added in culture medium, (ii) only NCNTs were added in culture medium, (iii) bacteria and NCNTs were both added in culture medium.

3. For the purpose of exploring the reuse feasibility of NCNTs after bioleaching reaction, the experiment was designed to test the reuse performance of acidified NCNTs.

\section{Analytical Methods}

During the bioleaching period, the $\mathrm{pH}$ in leached liquor was measured by a digital pH meter (Sartorius PB-10, SARTORRIUS, Germany). Redox potential was detected by electrode (XK30-HT1000, REX, China). $\mathrm{Fe}^{2+}$ was measured through a UV spectrophotometer (TU-1901, PERSEE, China) at $510 \mathrm{~nm}$, and the surface of NCNTs was observed using a SEM (S-4800, HITACHI, Japan). All graphs were drawn using origin 8.0.

Table 1. Elemental composition of WPCBs in different particle sizes.

\begin{tabular}{|c|c|c|c|c|c|c|}
\hline $\begin{array}{c}\text { Particle sizes } \\
(\mathrm{mm})\end{array}$ & $\begin{array}{c}\mathrm{Au} \\
(\mathrm{mg} / \mathrm{g})\end{array}$ & $\begin{array}{c}\mathrm{Ag} \\
(\mathrm{mg} / \mathrm{g})\end{array}$ & $\begin{array}{c}\mathrm{Cu} \\
(\mathrm{mg} / \mathrm{g})\end{array}$ & $\begin{array}{c}\mathrm{Zn} \\
(\mathrm{mg} / \mathrm{g})\end{array}$ & $\begin{array}{c}\mathrm{Sn} \\
(\mathrm{mg} / \mathrm{g})\end{array}$ & $\begin{array}{c}\mathrm{Ni} \\
(\mathrm{mg} / \mathrm{g})\end{array}$ \\
\hline$<1$ & 1.11 & 7.62 & 203.24 & 32.21 & 62.25 & 48.39 \\
\hline $1-2.5$ & 1.32 & 11.66 & 277.68 & 19.49 & 55.49 & 42.69 \\
\hline $2.5-4$ & 0.78 & 4.69 & 286.02 & 15.91 & 38.36 & 15.95 \\
\hline$>4$ & 0.50 & 5.66 & 339.05 & 14.82 & 32.48 & 9.19 \\
\hline
\end{tabular}




\section{Results and Discussion}

\section{Compatibility Test between NCNTs and $A$. ferrooxidans}

The leaching rate of copper in solution was made as an index for exploring the effects of different amounts of NCNTs to A. ferrooxidans. As shown in Fig. 1, the results indicated that the leaching rate of copper in all experimental groups increased during the extension of the leaching time. NCNTs could improve the leaching rate of copper from WPCB, and with the increased amount of NCNTs its ability to promote the leaching rate first increased before decreasing. In $50 \mathrm{ml}$ culture medium, the optimal amount of NCNTs was $0.04 \mathrm{~g}$.

The reasons for these results might be the large surface areas of NCNTs, which could increase the contact areas between bacteria and WPCB powder, then make the fixed reaction time extended between bacteria and WPCBs. Bacteria gathered on the surface of NCNTs, and NCNTs could be satisfactorily adsorbed on the surface of WPCB powder. Therefore, this process increased the bacteria residence time in WPCB powder, so that there was sufficient contact time between bacteria and WPCB powder, and the leaching rate of copper in all experimental groups increased respectively. On the other hand, a large amount of NCNTs would inhibit bacterial growth. The distribution of NCNTs in the culture medium was divided into two parts: one part of NCNTs was dispersed in the solution uniformly, and the other part would float at the surface of culture medium (so it was necessary to control the amount of NCNTs). The excessive NCNTs could block carbon dioxide entering the culture medium and the phenomenon of agglomeration would appear, which was not conducive to the normal growth of bacteria. This was similar to the result in Xie's study [18].

In summary, the bioleaching rate first increased and then decreased during the increased amount of NCNTs.

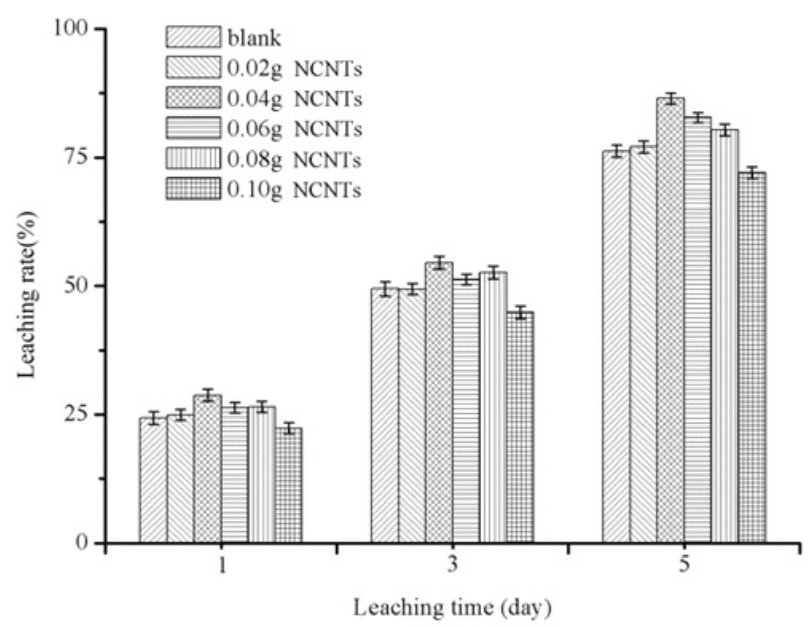

Fig. 1. Leaching rate of copper during leaching time when different amounts of NCNT were added.

\section{Effects of NCNTs in the Bioleaching Process}

\section{The Change of $\mathrm{pH}$ during \\ the Bioleaching Process}

Many factors affect $\mathrm{pH}$ variation, including the generation of bacterial metabolites and chemical reactions in the culture medium. Therefore, detection of $\mathrm{pH}$ changes can reflect the reaction process. Fig. 2 shows the change of $\mathrm{pH}$ during the bioleaching process. In the experiment that only added NCNTs, the $\mathrm{pH}$ in culture medium rose to nearly 3.5 quickly and remained unchanged during the extension of the leaching time. For the experiment in which only bacteria was added, culture medium $\mathrm{pH}$ rose to near 3.0 after 24 hours of bioleaching, then dropped to 2.5 when cultured for five days. For the experiment in which bacteria and NCNTs were both added, the culture medium $\mathrm{pH}$ first rose to nearly 2.7 before gradually dropping to 2.2. Overall, under these three conditions of bioleaching, $\mathrm{pH}$ first rose and then gradually declined after 24 hours, and the order of $\mathrm{pH}$ value was: only NCNTs $>$ only bacteria $>$ NCNTs and bacteria.

The reasons for this phenomenon might be that the transition for $\mathrm{Fe}^{2+}$ to $\mathrm{Fe}^{3+}$ was a process of acid consumption at the start of the reaction, so the $\mathrm{pH}$ in culture medium suffered varying degrees of rising at the beginning of all experimental groups. After a period of time, $\mathrm{Fe}^{3+}$ began to hydrolyze and $\mathrm{H}^{+}$was generated, so the $\mathrm{pH}$ in culture medium gradually declined. Another possible reason for the second result might be the large specific surface in NCNTs, so free $\mathrm{H}^{+}$in culture medium was absorbed by NCNTs, and the free $\mathrm{H}^{+}$was declined in the culture medium caused a $\mathrm{pH}$ value higher than the other two groups. Moreover, bacteria might have a stress reaction under the effect of NCNTs, and the secondary metabolites that were produced by bacteria contained some acid substances. The stress reaction might make the acid

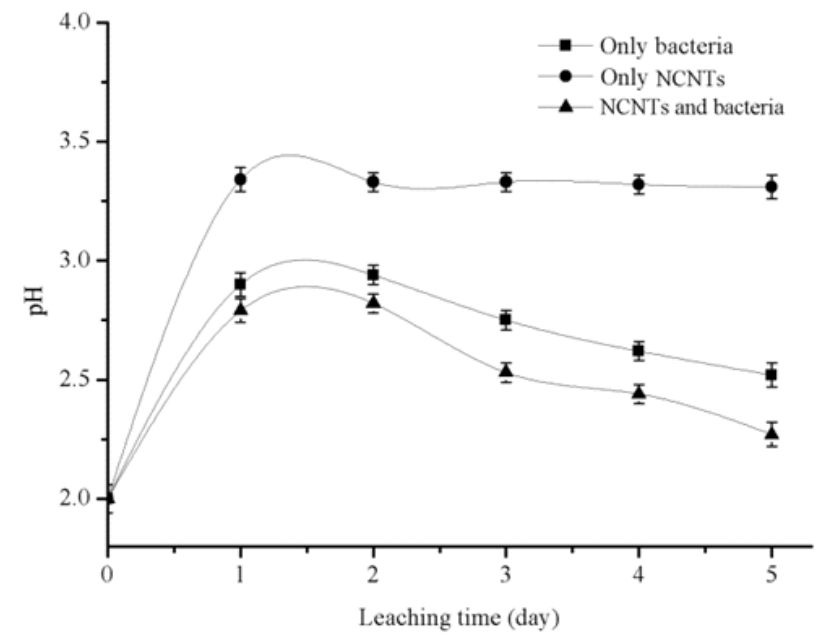

Fig. 2. Variations of $\mathrm{pH}$ in culture medium during the bioleaching process. 
intracellular substances be released into the extracellular ones, and this process made the concentration of $\mathrm{H}^{+}$ increase in culture medium, so the group where NCNTs and bacteria were both added had the lowest $\mathrm{pH}$ value.

\section{The Change of ORP during the Bioleaching Process}

Redox reaction can be reflected by the variation of ORP in leaching solution. Fig. 3 showed the variation in ORP during the bioleaching process. In this figure, the leaching time could be divided into two periods. In the first period, the curves of ORP dropped with the increase of leaching time, and the experiment in which only NCNTs were added had the largest decline compared with the other two groups. Besides, this phenomenon was diametrically opposite to the change of $\mathrm{pH}$ in the culture medium. In the second period, the curves of ORP ascended with the extension of leaching time. Among these three experiments, when NCNTs and bacteria were added simultaneously, the ORP was always higher than the other two groups. The overall trends were different with the variation of $\mathrm{pH}$ in culture medium. During five days of leaching, the order of ORP value was: NCNTs and bacteria $>$ only bacteria $>$ only NCNTs.

There were two reasons for the ORP variation during the bioleaching process. On one hand, as previously said, ORP value in the culture medium was decided by many factors, for instance the ratio between oxidized material and reduced material, temperature, $\mathrm{pH}$, and so on. Fresh culture medium had the maximum value of the ORP, and the ORP value was declined gradually during the extension of the leaching time. The variation extent of ORP in three experiments was inconsistent, and these were the results of the combined action among oxidized material, reduced material, and $\mathrm{pH}$ in culture medium. On the other hand, the large specific surface areas that NCNTs had could offer a place to react between bacteria and WPCB powder, then some oxidation substances were absorbed in these areas,

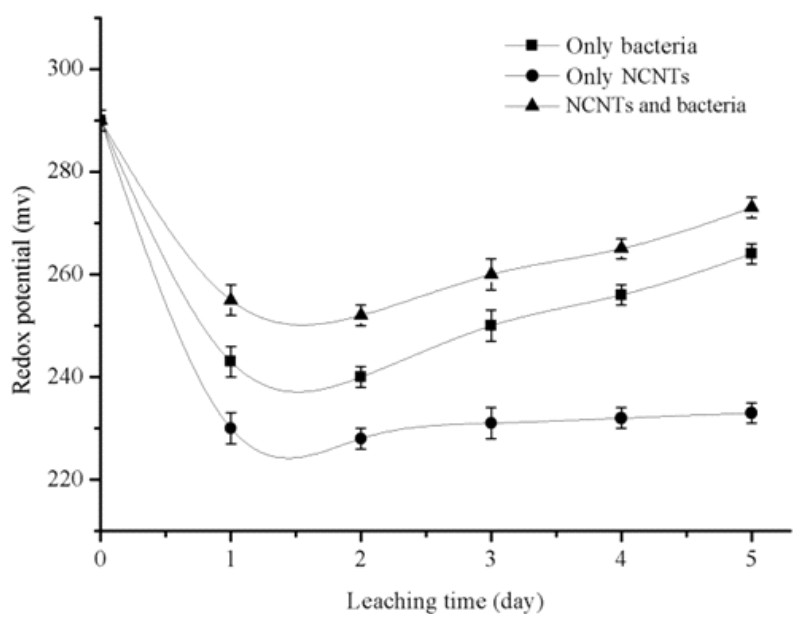

Fig. 3. Variations of ORP in culture medium during the bioleaching process.

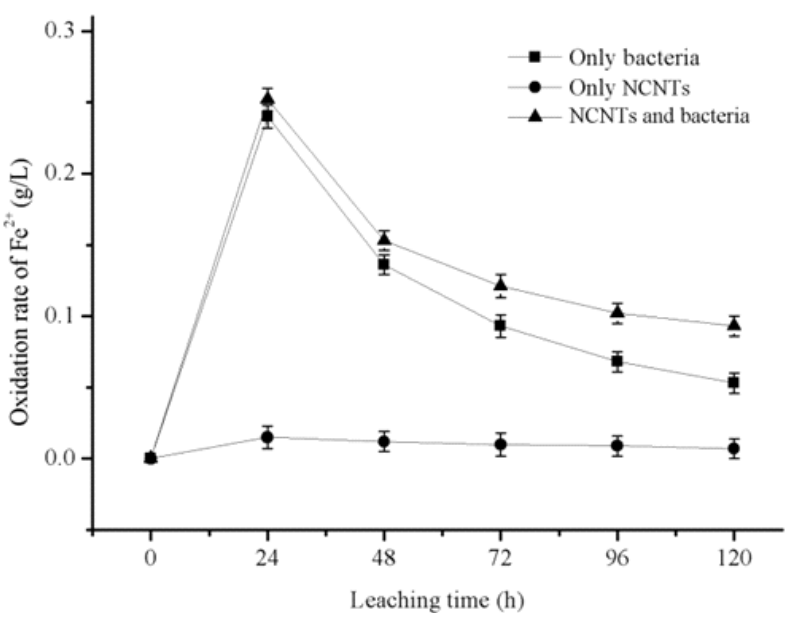

Fig. 4. Variations of $\mathrm{Fe}^{2+}$ oxidation rates in culture medium during the bioleaching process.

such as $\mathrm{Cu}^{2+}$ and $\mathrm{Fe}^{3+}$. Therefore, oxidation substances in the solution could be maintained for a long time, so the group in which NCNTs and bacteria were both added had the highest ORP value.

\section{Variation of $\mathrm{Fe}^{2+}$ in the Bioleaching Process}

Fig. 4 indicates that the oxidation rate of $\mathrm{Fe}^{2+}$ was at a lower level and basically remained unchanged in the group in which only NCNTs were added. The variations trend of $\mathrm{Fe}^{2+}$ were the same in other two groups, but the oxidation rate of $\mathrm{Fe}^{2+}$ in the group in which NCNTs and bacteria were both added was the highest. These phenomena could be divided into two periods. During 24 hours the oxidation rate of $\mathrm{Fe}^{2+}$ ascended with the extension of leaching time, then dropped gradually after 24 hours. The oxidation rate of $\mathrm{Fe}^{2+}$ declined to $0.1 \mathrm{~g} /(\mathrm{L} \cdot \mathrm{h})$ after five days of bioleaching. Seen from Fig. 4, the conclusion was that the oxidation rate of $\mathrm{Fe}^{2+}$ in the group in which NCNTs and bacteria were both added was the highest.

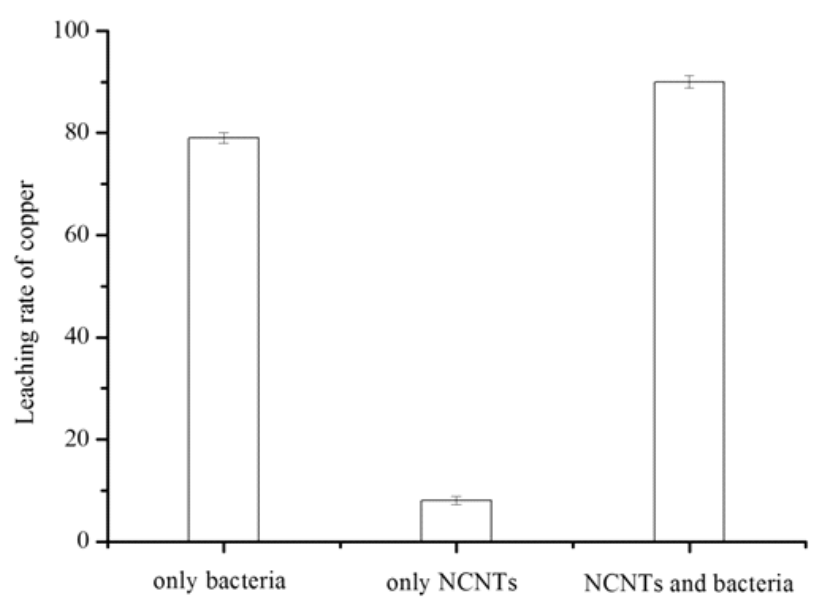

Fig. 5. Conditions of experiment. 
The main reasons for this phenomenon might be the $\mathrm{Fe}^{2+}$ in the group in which only NCNTs were added and were only oxidized by air. Shown in Fig. 4, this phenomenon appeared to demonstrate that the oxidation by air was very weak. In addition to air oxidation, the action of bacteria was also the reason for the other two groups, so the variation trends in these two groups were the same. The action of bacteria played a major role due to bacterial metabolites that could promote the conversion between $\mathrm{Fe}^{2+}$ and $\mathrm{Fe}^{3+}$. Furthermore, the addition of NCNTs could improve this conversion between $\mathrm{Fe}^{2+}$ and $\mathrm{Fe}^{3+}$ to some extent, and resulted in the higher $\mathrm{Fe}^{2+}$ oxidation in the group in which NCNTs and bacteria were added simultaneously.

\section{Leaching Rate of Copper under Different Conditions of Bioleaching}

Fig. 5 indicates that nearly $80 \%$ of copper was leached after five days of reaction in the group in which only bacteria was added, but when NCNTs and bacteria were both added in the culture medium, about $90 \%$ of copper was leached after five days of reaction. If only NCNTs were added to the culture medium, the leaching rate of copper was only $5 \%$. The addition of NCNTs certainly promoted the leaching rate of copper from WPCB powder.

The possible reasons for these phenomena might be the dissociative $\mathrm{Cu}^{2+}$ in culture medium that was absorbed by NCNTs, and this reduced the concentration of $\mathrm{Cu}^{2+}$ in the culture medium, and this process could not enable $\mathrm{Cu}^{2+}$ in reaching saturation state in the culture medium, so the reaction always generated $\mathrm{Cu}^{2+}$. This phenomenon could promote the leaching rate of copper to some extent from WPCB powder. On the other hand, NCNTs have a good ability to transfer electrons; therefore, the electron transfer rate in the culture medium was sped up by the NCNTs, and at last the leaching reaction was promoted. When NCNTs and bacteria were both added to the culture medium, the leaching rate of copper was the highest of all experimental groups.

\section{The Recycling Feasibility of NCNTs}

On one hand, NCNTs are expensive, but on the other it carries a potential risk to the environment, so NCNTs must be recycled. On the basis of the experiment above, a method for acid treatment was used to remove impurities in NCNTs. The filtrate was filtered in order to collect NCNTs. Fig. 6 showed the SEM scanning of NCNTs which were in a different state. The surface structure of NCNTs could be seen clearly from Fig. 6a, and the surface of NCNTs was of uneven thickness. According to the result in Fig. 6b, there were some bacterial residues, iron precipitates, and metal ions that were already leached in culture medium adhering to the surface area in the NCNTs. When treated with acid, the NCNTs could return to the original state as shown in Fig. 6c, and the surface of NCNTs became uniform thickness.
NCNTs without any processing and NCNTs with acid treatment after bioleaching were added to the bioreactor, which already contained bacteria and WPCB powder. The results as shown in Fig. 7, when NCNTs without any processing were added in culture medium after five days of bioleaching, indicate a leaching rate of copper of nearly $90 \%$. When NCNTs with acid treatment were added in culture medium, after five days of bioleaching the leaching rate of copper was nearly $88 \%$. So, after acid treatment toward NCNTs, its ability to promote the leaching rate of

a)

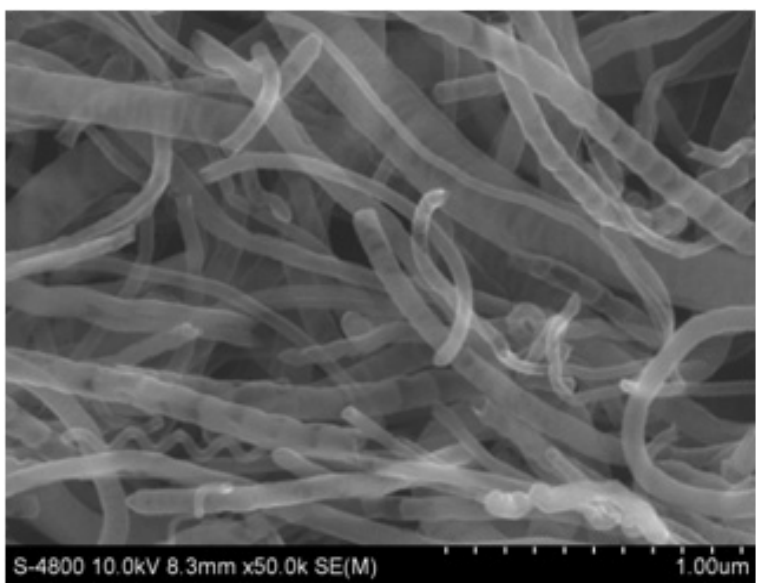

b)

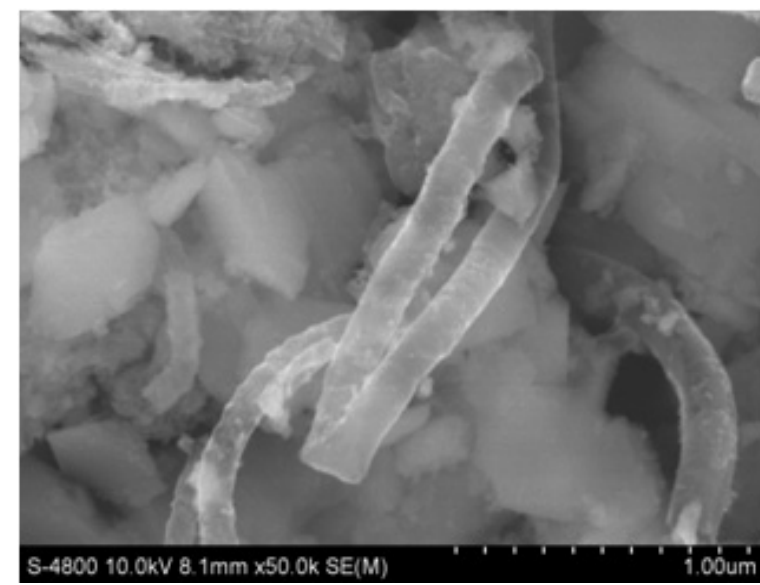

c)

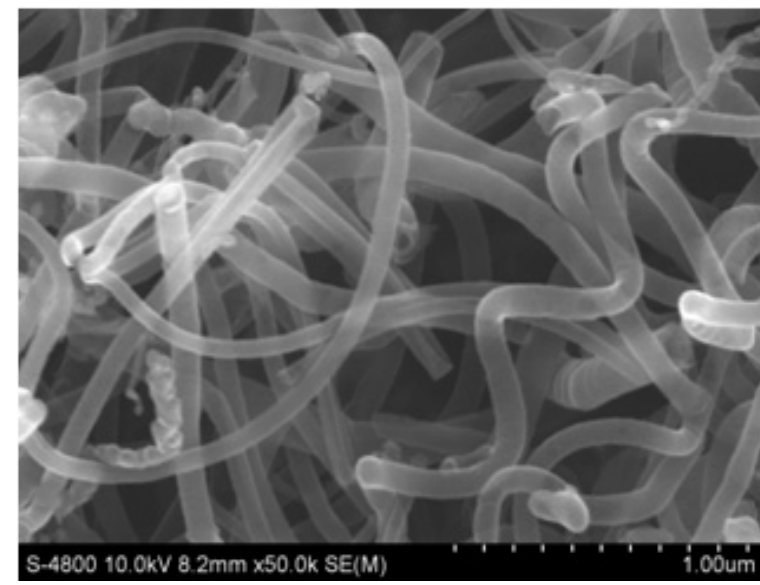

Fig. 6. SEM scanning of NCNTs: a) without any processing, b) after reaction with bacteria, c) after acid treatment. 


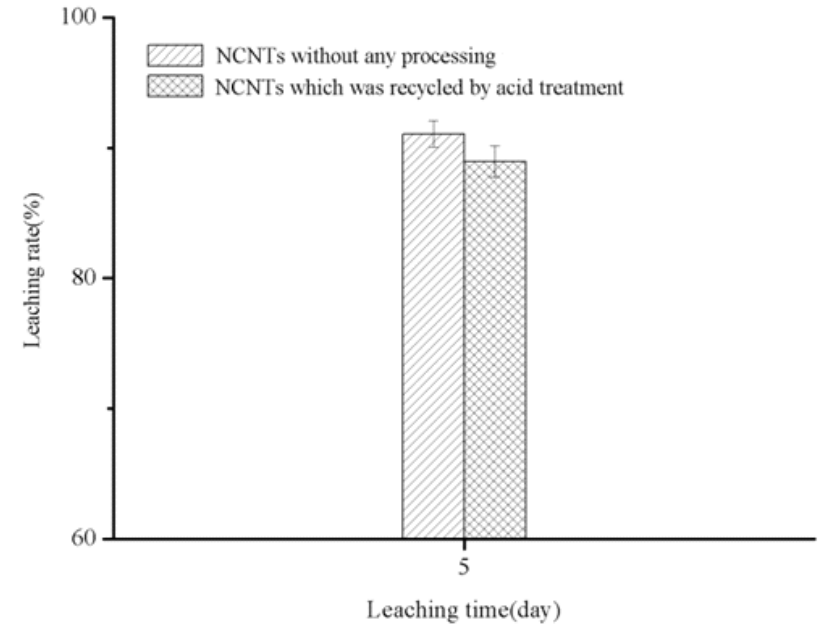

Fig. 7. Leaching rates of copper after five days leaching time when different states of NCNTs were added.

copper had a certain degree of decline, but not obviously. The conclusion showed that NCNTs could be reused after acid treatment, and it had almost no effect on catalyzing A. ferrooxidans bioleaching copper from WPCB powder.

\section{Conclusions}

The low leaching efficiency limited $A$. ferrooxidans bioleaching copper from WPCB in its industrial applications. The catalytic role of NCNTs in bioleaching copper from WPCB by $A$. ferrooxidans was investigated in this research. The results indicated that a certain amount of NCNTs had good compatibility with $A$. ferrooxidans, and it had the best consistency when added to $0.04 \mathrm{~g} \mathrm{NCNTs}$ in $50 \mathrm{ml}$ solution. NCNTs could promote nearly $10 \%$ of the copper leaching rate in the bioreactor compared with the experimental group to which NCNTs were not added, and these laid the foundation for NCNT applications in the field of hydrometallurgy.

When the NCNTs that were collected after the reaction were treated with acid, its ability to promote the bioleaching rate of copper had a certain - but not obvious - degree of decline of about $2 \%$ lower than the group in which the NCNTs were not treated with acid, so the NCNTs could be recycled. NCNTs can be used to improve the $A$. ferrooxidans leaching efficiency from WPCB in the future, and the experimental mode used in this study can be used in other fields of hydrometallurgy.

\section{Acknowledgements}

The financial support for this work from the National Natural Science Foundation of China (Grant No. 21307080), Strategic Emerging Industry in Guangdong Province (Grant No. 2012A032300017), and the Academic Discipline Project of Shanghai Polytechnic
University (Grant No. XXKZD1062), the Science and Technology Development Fund Project of Shanghai Polytechnic University (Grant No. EGD16XQD09) are gratefully appreciated.

\section{References}

1. CARLOUS P., BERGMANN P.A. Electronic waste recycling techniques. Springer, Brazil, 2015.

2. EYUP Y., JUDE A.O., PAUL T.W. Chemical recycling of printed circuit board waste by depolymerization in sub-and supercritical solvents. Waste Biomass Valori. 6, 960, 2015.

3. COLMER A.R., HINKLE M.E. The role of microorganisms in acid mine drainage: a preliminary report. Sci, 106, 254, 1947.

4. ZHOU H.B., ZENG W.M., YANG Z.F., XIE Y.J., QIU G.Z. Bioleaching of chalcopyrite concentrate by a moderately thermophilic culture in a stirred tank reactor. Bioresour. Technol. 100, 516, 2009.

5. WU A., YIN S., WANG H., QIN W., QIU G. Technological assessment of a mining-waste dump at the Dexing copper mine, China, for possible conversion to an in situ bioleaching operation. Bioresour. Technol. 100, 1933, 2009.

6. GU W.H., BAI J.F., DAI J., ZHANG C.L., YUAN W.Y., WANG J.W. Characterization of Extreme Acidophile Bacteria (Acidithiobacillus ferrooxidans) Bioleaching Copper from Flexible PCB by ICP-AES. J. Spectro. 2014, 4, 2014.

7. HUANG J.X., CHEN M.J., CHEN H.Y., CHEN S., SUN Q. Leaching behavior of copper from waste printed circuit boards with Bronsted acidic ionic liquid. Waste Manage. (Oxford) 34, 485, 2014.

8. LIANG G.B., TANG J.H., LIU W.P., ZHOU Q.F. Optimizing mixed culture of two acidophiles to improve copper recovery from printed circuit boards (PCBs). J. Hazard. Mater. 250, 243, 2013.

9. KARWOWSKA E., ANDRZEJEWSKA-MORZUCH D., LEBKOWSKA M., TABERNACKA A., WOJTKOWSKA M., TELEPKO A., KONARZEWSKA A. Bioleaching of metals from printed circuit boards supported with surfactant producing bacteria. J. Hazard. Mater. 264, 206, 2014.

10. ARSHADI M., MOUSAVI S.M. Simultaneous recovery of $\mathrm{Ni}$ and $\mathrm{Cu}$ from computer printed circuit boards using bioleaching: Statistical evaluation and optimization. Bioresour. Technol. 174, 236, 2014.

11. LIANG G.B., MO Y.W., ZHOU Q.F. Novel strategies of bioleaching metals from printed circuit boards (PCBs) in mixed cultivation of two acidophiles. Enzyme Microb. Technol. 47, 325, 2010.

12. BAI J.F., WANG J.W., XU J.Q., ZHOU M.Y. Microbiological recovering of metals from printed circuit boards by Acidithiobacillus ferrooxidans. IEEE, Inter Sympo. 2009. DOI: 10.1109/ISSST.2009.5156716.

13. WANG X.G., SUN Y., YANG H.W. Influence of chemical modification treatment on structure and activity of multiwalled CNTs in catalytic wet air oxidation of phenol. Chin. J. Enviro. Eng. 6, 4403, 2012.

14. NIU J.J., WANG J.N., JIANG Y., SU L.F., MA J. An approach to CNTs with high surface area and large pore volume. Micropor Mesopor Mater. 100, 03, 2007.

15. CHANTELLE L.P., CLARENCE S.Y., SUNNY E.I., RUMBOLD K., PILLAY V. The cellular response of Saccharomyces cerevisiae to multiwalled CNTs (MWCNTs). J. Saudi. Chem. Soc.19,149, 2015. 
16. MUNOZ E., DALTON A.B., COLLINS S., ZAKHIDOV A.A., BAUGHMAN R.H., ZHOU W.L., HE J., OCONNOR C.J., MCCARTHY B., BLAU W.J. Synthesis of SiC nanorods from sheets of single-walled carbon nanotubes. Chem. Phys. Lett. 359, 400, 2002.

17. CHATTERJEE S., LEE M.W., WOO S.H. Adsorption of congo red by chitosan hydrogel beads impregnated with carbon nanotubes. Bioresour. Technol. 101, 1804, 2010.

18. XIE W.H., JIANG C.H., CHENG Y., LIU H.Q., XU X.P., CHEN Z.L. Toxic effect of CNTs on growth of Acidithiobacillus ferrooxidans and mechanism of toxication. Chin. J. Enviro. Eng. 7, 3675, 2013. 